تأثير كاربرد ماده زايكوسيل بر ميزان آب مصرفى و عملكرد گياه فلفل قلمى

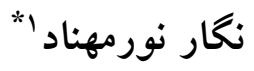

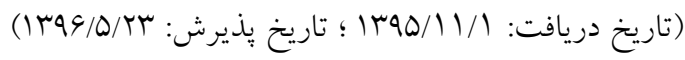

حكکنه

با توجه به وضعيت بحران آب در كشور، ارائه راهكارهايى جهت كاهش مصرف آب در بخش كشاورزى اهميت زيـادى دارد. زايكوسـيل

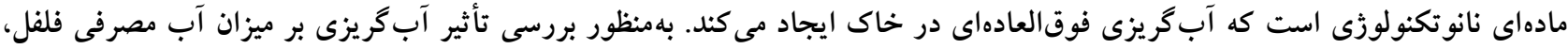

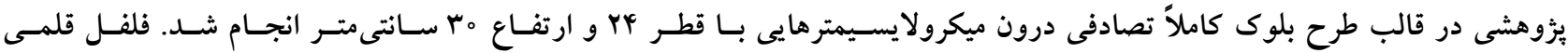
(Capsicum annuum L.)

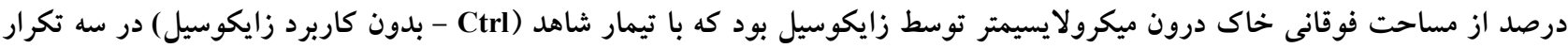

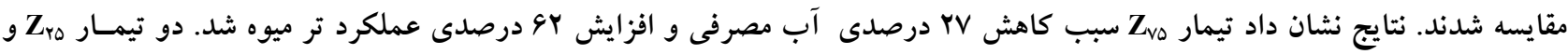

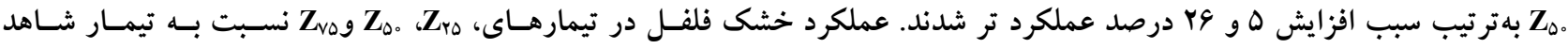

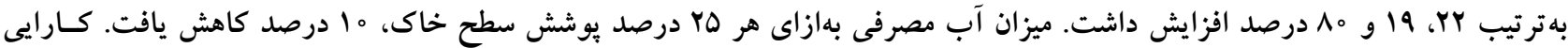

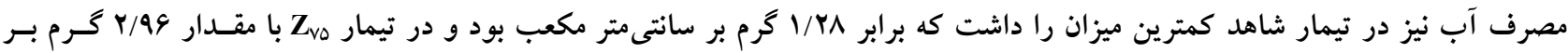

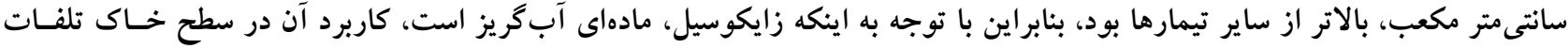

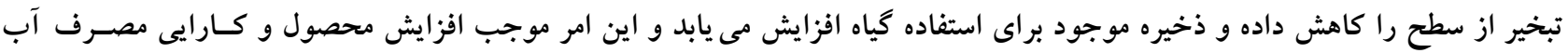
مى شود.

وازههاى كليدى: آبگريز، كارايى مصرف آب، زايكوسيل، عملكرد، فلفل 
آب كريزى خاك زمانى اتفاق مىافتـد كـه خـاك بـهـــور كامـل

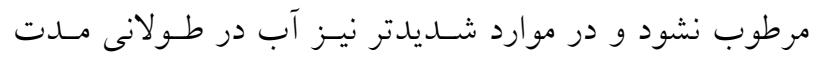

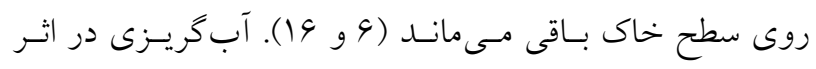

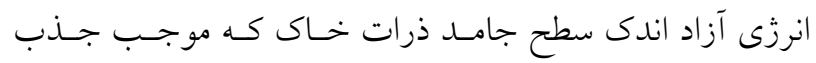

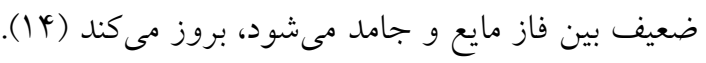

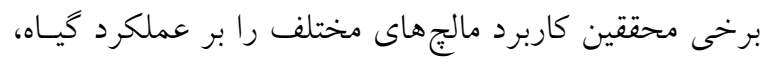

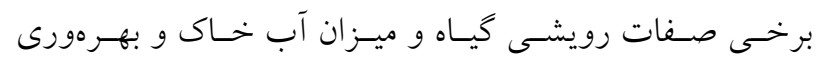

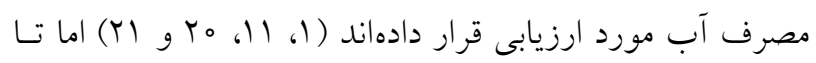

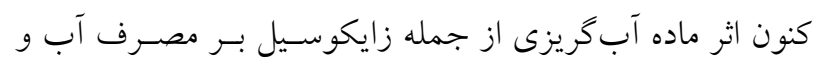
رشد كَاه بررسى نشده است. زايكوسيل محصولى است نانوتكنولوزى، شفاف، قابـل حـل

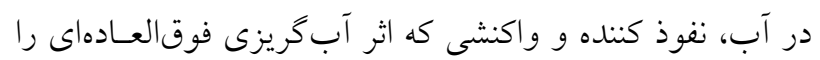

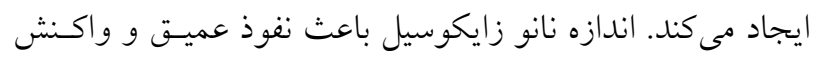

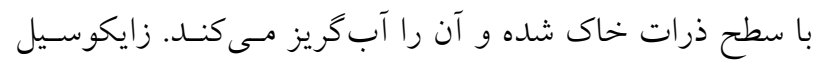

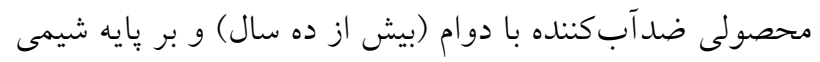

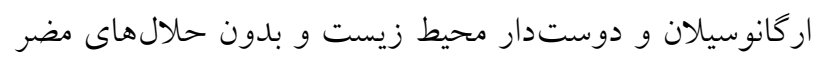

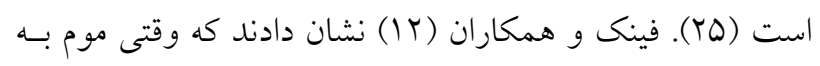

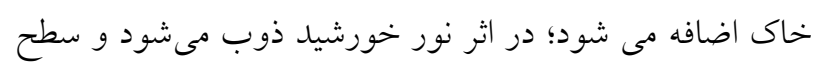

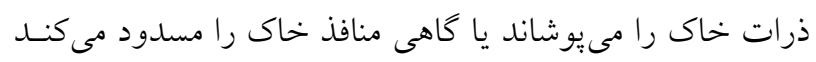

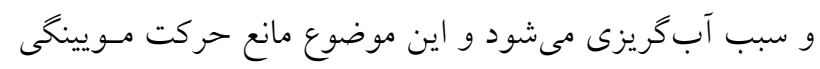

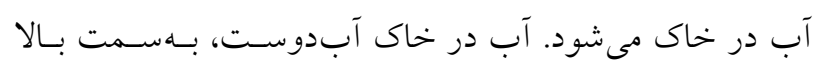

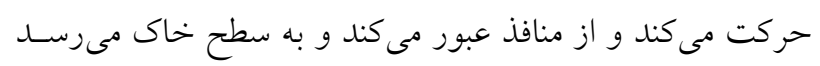

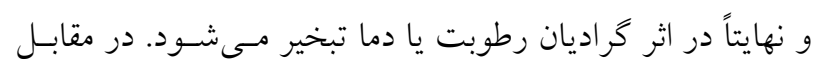

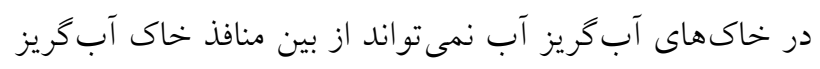

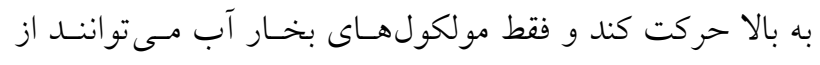

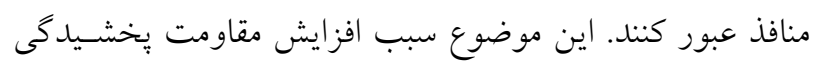

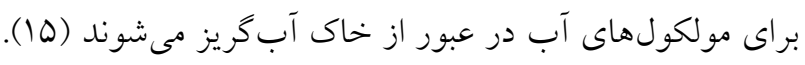

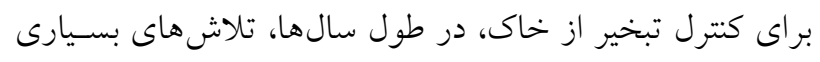

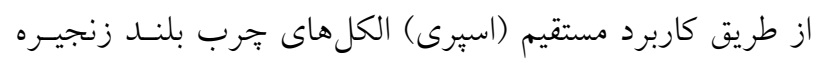
در خاك، واكس، يلاستيك و غيره انجام شد. در سالهاى اخيـر

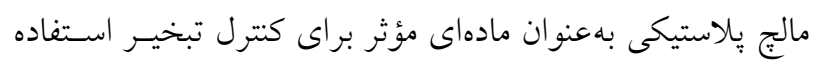

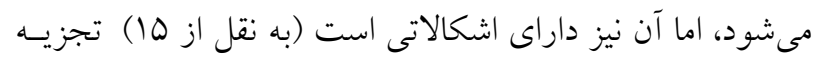

فلفل كياهى كرمادوست و حساس به تنش آبى است. كمبود آب

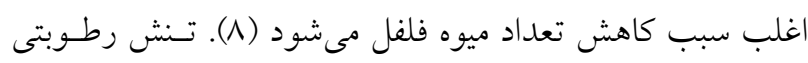

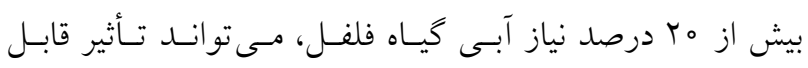

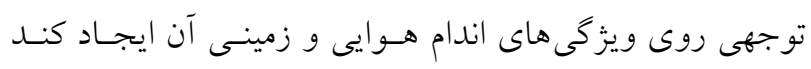

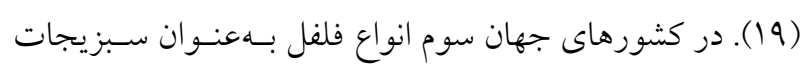

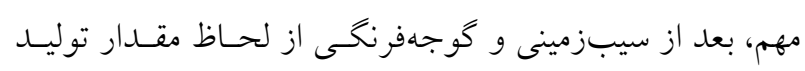

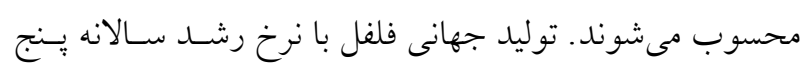

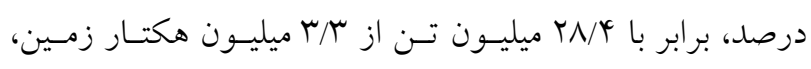
بهصورت ميوه خشك و ميوه سبز است (ه (1). عكس العمل كيـاه

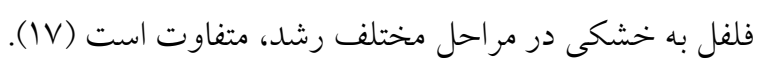

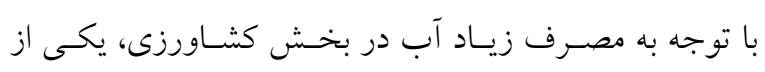

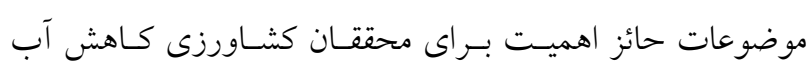

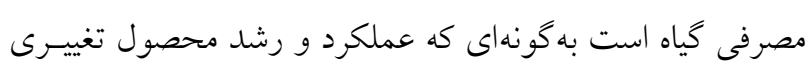

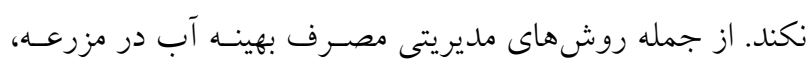

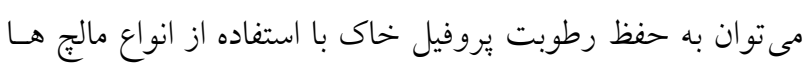

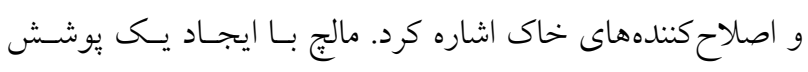

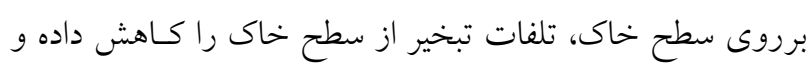

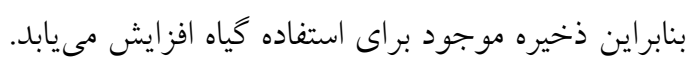

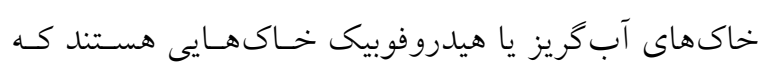

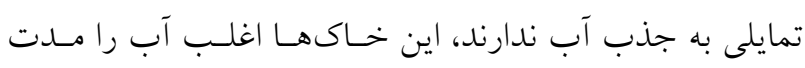

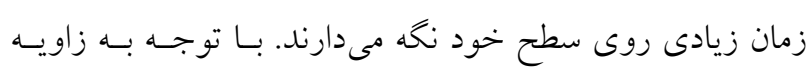

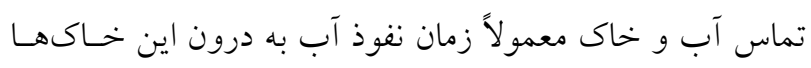

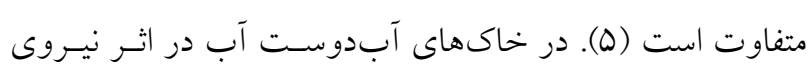

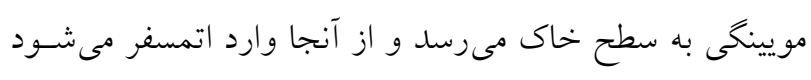

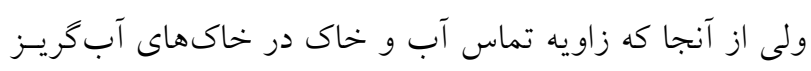

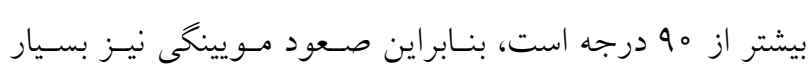

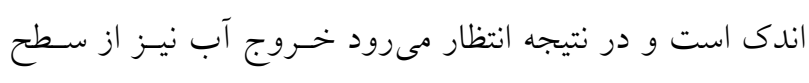

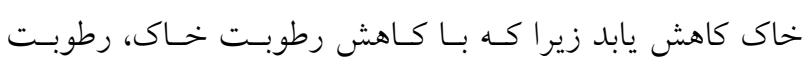

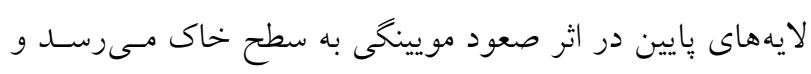

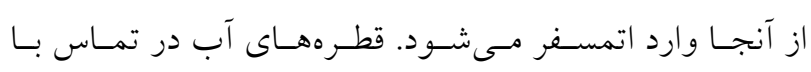

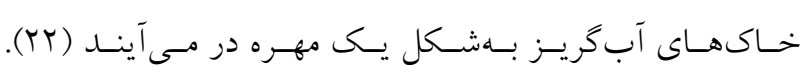


جدول ا. خصوصيات فيزيكى و شيميايى خاك

\begin{tabular}{|c|c|c|c|c|c|c|c|c|}
\hline تخلخل & ظرفيت زراعى & مواد آلى & קجالى حقيقى & جَخالى ظاهرى & 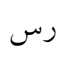 & سيلت & 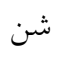 & 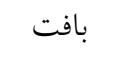 \\
\hline (درصد) & (كرم بر گرم) & (درصد) & \multicolumn{2}{|c|}{ (كرم بر سانتىمتر مكعب) } & & درصد) & & \\
\hline$\Delta \wedge$ & $\circ / \mu_{0}$ & $r / \Delta r$ & $r / T r$ & $|/ 4|$ & щ & re & rA & لو لوم رسى \\
\hline
\end{tabular}

جدول r. دادههاى شاخص هواشناسى در منطقه آزمايشى در طول دروه رشد

\begin{tabular}{|c|c|c|c|c|c|c|}
\hline الى با مهر & شهر يور & مرداد & تير & خرداد & از || ارديبهشت & تاريخ \\
\hline $19 / 4$ & $T Y / \mu$ & TV & TN/G & TY & $r \mid r$ & متوسط دما (Co $)$ \\
\hline r1/9 & TV/V & $T Y / \mu$ & Tr/r & $r T / 0$ & $r q / \mu$ & متوسط رطوبت (\%) \\
\hline$\circ \%$ & $\circ \%$ & $\%$ & $\circ$ & 。 & $\circ / \wedge$ & بارش (mm) \\
\hline $9 / 0$ & $9 / 1$ & $10 / 0$ & $10 / 9$ & $11 / 0$ & $\Lambda / \Lambda$ & ساعات آفتابى \\
\hline$Q / Y$ & $\varphi / 4$ & $r / 0$ & $0 / 0$ & $9 / \pi$ & $V / 4$ & سرعت باد (m/s) \\
\hline
\end{tabular}

تيمارهاى آزمايشى شامل يوشش هل، مه و VQ درصــ از كـل

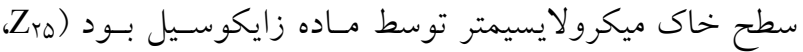

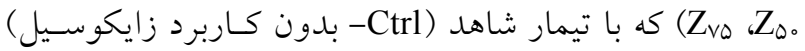

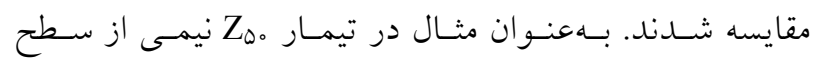

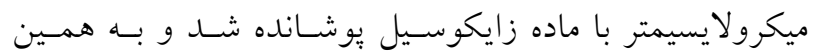

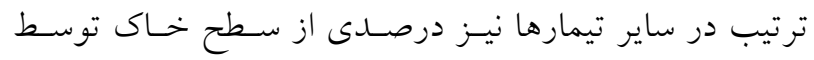

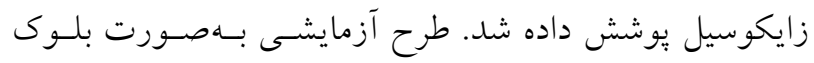

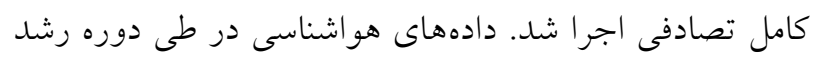
در جدول (Y) آورده شده است.

\section{آمادهسازى زايكوسيل}

بهمنظور تهيه خاك آبكريز توسط زايكوسيل، مـاده زايكوسـيل

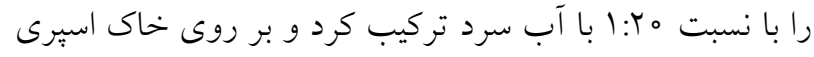

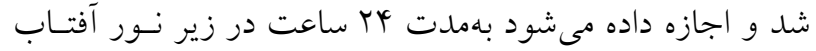

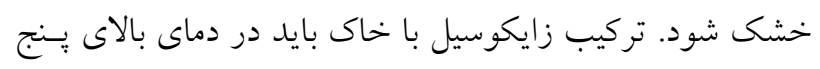

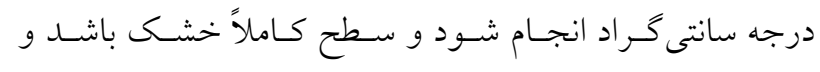

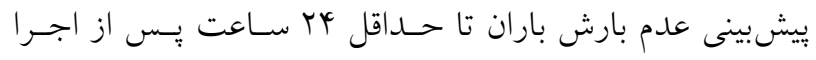

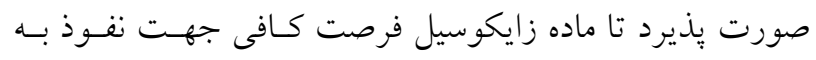
ذرات خاك را داشته باشد (TQ).
مالج بلاستيكى مدت زمان زيادى طول مى كشد و البتـه كـاربرد

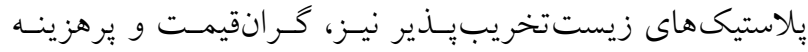
است (YY). بنابراين در اين يزولهش به بررسى اثـر كـاربرد مـاده آبكَريز زايكوسيل بر مصـرف آب، نخهاشــت آن در خـاك و تأثير آن بر عملكرد فلفل قلمى يرداخته شد.

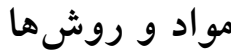

بهمنظور بررسى اثر ماده آبكريز زايكوسيل بر ميزان تبخيـر از

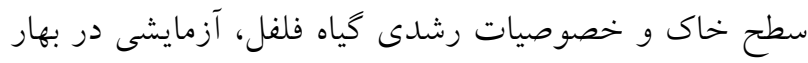

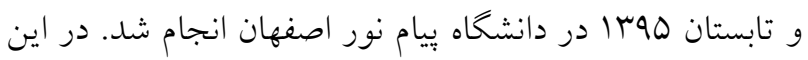

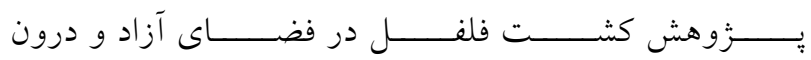

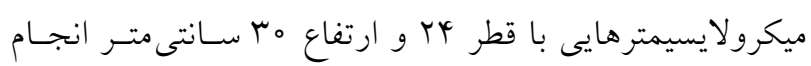

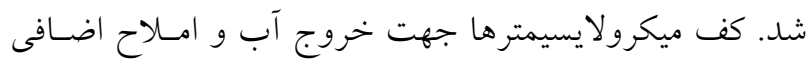

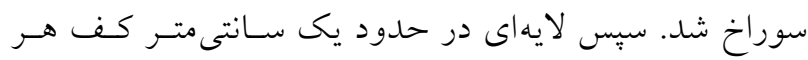

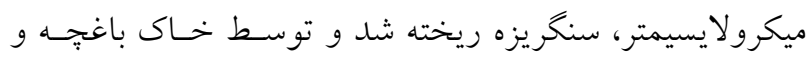

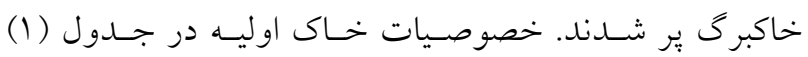
آورده شده است. نشاءهاى همسن و هم اندازه فلفل قلمسى در خر

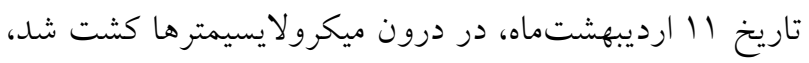
سبس بر روى ميكرولايسيمترها مـاده زايكوسـيل ريختـه شـــ. 
مىشدند تا اختلاف وزن هر كدام از آنها با حالت ظرفيت زراعى تعيين شود. سيس براى رساندن هر كدام از آنها بهحالت ظرفيت زراعسى، مقـدار آب لازم از رابطـه إمحاسـبه و آبيـارى انجـام

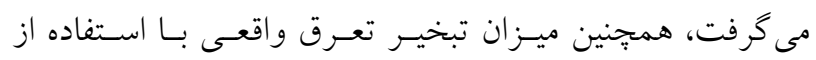

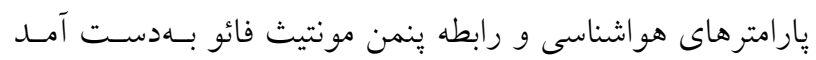
و با توجه به مقدار كاهش وزن ميكرولايسيمتر در هـر روز، له مقدار تبخير تعرق در هر تيمار نيز تعيين شد.

\section{تعيين وزن خشك ميوه و ريشه}

براى تعيين وزن خشك ميوههــا نيـز از هـر تيمـار نمونـههـايى برداشت شد و در آون با دماى Vo درجه سـانتى گـر اد قـرار داده شد و يس از خشك شدن درصد وزن خشك و ميزان آب آنهـا

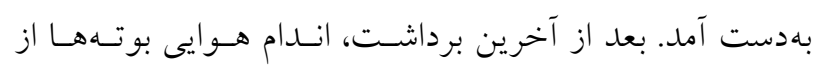

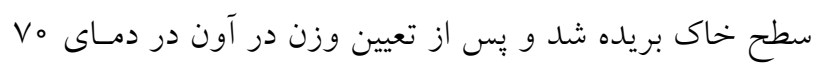

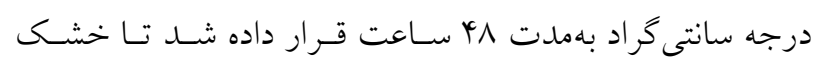
شوند. بعد از جداسازى ريشهها از خاك، بـهدقـت بـا اسـتفاده از V. فشار آب بهخوبى شسته و تميـز شـدند و در آون در دمـاى

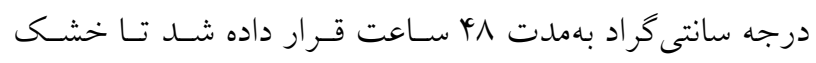
شوند و به اين ترتيب وزن خشك آنها توسط ترازوى ديجيتـالى

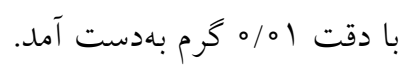

\section{كارايى مصرف آب}

نمايهاى كه براى كارايى مصرف آب بهكار مىرود مفهوم زراعى آن است كه بهنـام كـارايى كلى و زراعسى مصـرف آب ناميـده مىشود (WUE $\mathrm{WUE}_{\mathrm{ag}}=\mathrm{P} / \mathrm{W}$

در اين رابطه P توليد محصول (يا بر حسب مـاده خشك و يـا

محصول قابل ارائه به بازار) و W مقدار آب مصرفى است.

\section{تجزيه و تحليل نتايج}

بهمنظور تجزيه و تحليل نتايج از نرم|فـزار SAS9 اسـتفاده شـــ و بهكمى اين نرمافزار، جدول تجزيه واريانس صفات مختلف تهيـه
تعيين وضعيت آبكريزى خاك بهدست آمده براى تعيين آبكريـزى از روش آزمـايش قطـره آب (9) اسـتفاده

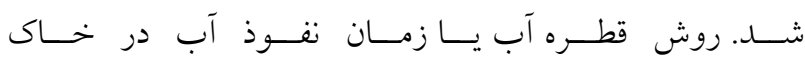
شامل قرار دادن سه قطره آب (Water Drop Penetration Time) مقطر (01 ميكروليتر) توسط قطرهجكان بزشكى روى سطح صاف خاى و اندازهكيرى مدت زمان نفوذ و جذب قطرهها توسط خـاى اسـت (9 و با (1). ايـن روش تقريبـاً هميشـهـ مـورد اسـتفاده قــرار

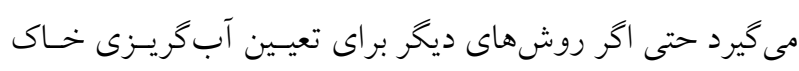
بهكار برده شود، اين روش قـادر بـهـ جداسـازى خـاكهــا از نظــر

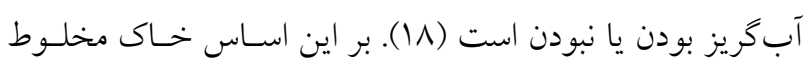
شده با زايكوسيل در كروه آبكريز بسيار شديد قرار كرفت.

تعيين آب مورد نياز گياه براى تعيين مقدار آب مورد نيـاز گيـاه در هـر بـار آبيـارى، ميـزان

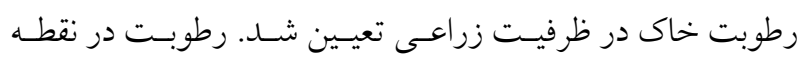
ظرفيت زراعى قبلاً از طريق دستگاه صفحات فشارى در آزمايشكاه

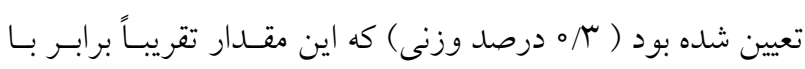

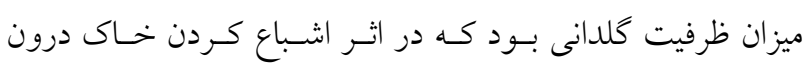

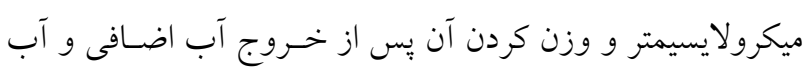

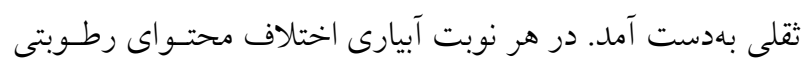

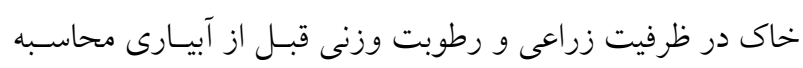

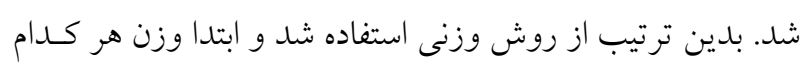

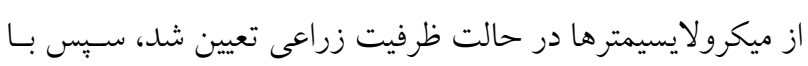

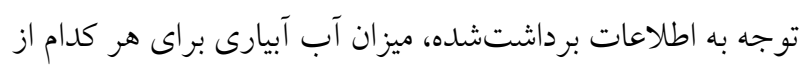

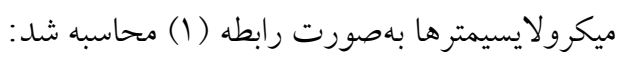
$\mathrm{M}_{\mathrm{wi}}=\mathrm{M}_{\mathrm{fci}}-\mathrm{M}_{\mathrm{i}}$

از اين رابطه M مقدار آب لازم براى آبيارى ميكرولايسيمتر iام

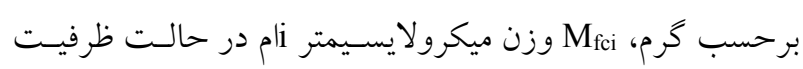

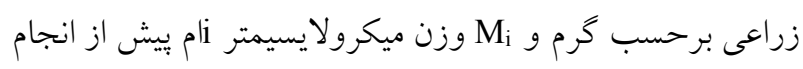
آبيارى برحسب كرم است.

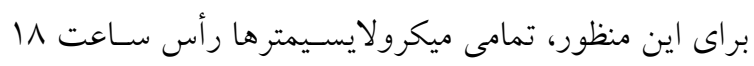

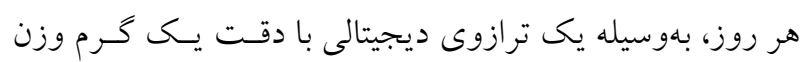


زايكوسيل بيشتر از تيمار شاهد بود. بيشترين تعـداد ميـوه در تيمـار

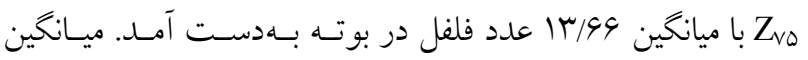

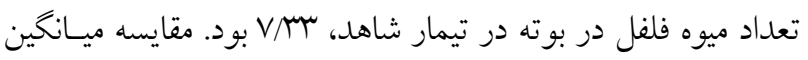

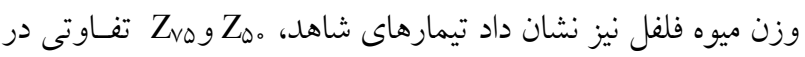

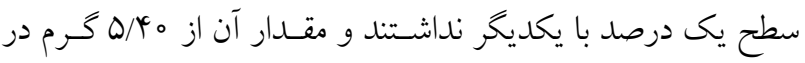

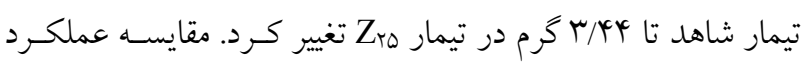

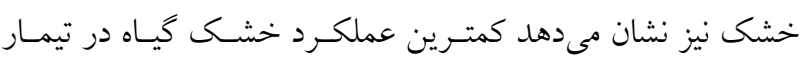

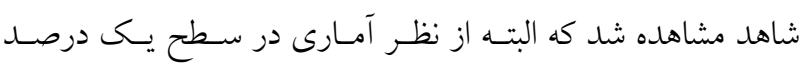

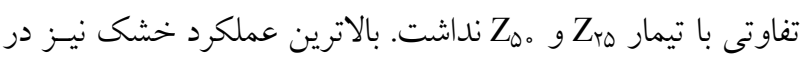

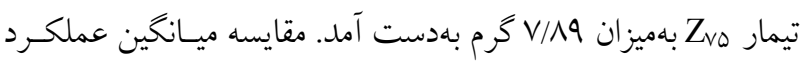

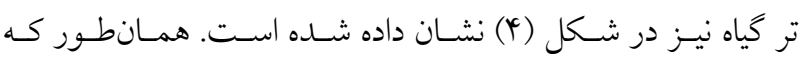

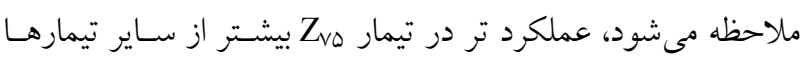

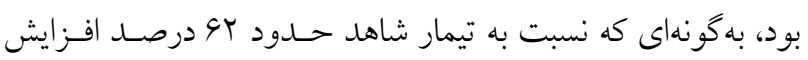

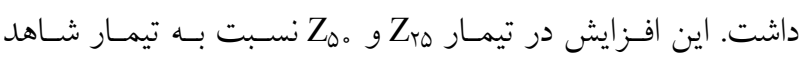

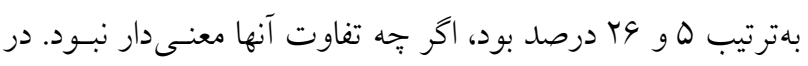

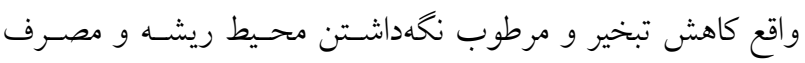

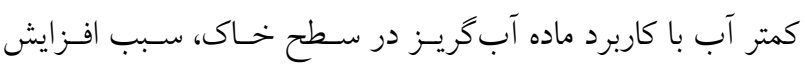

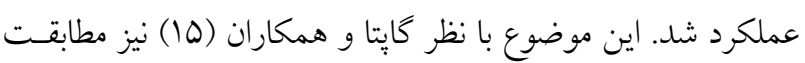

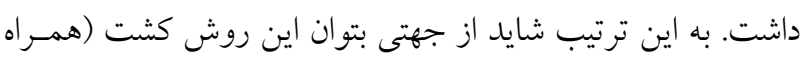

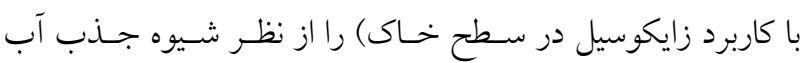

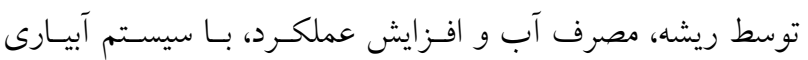
قطرهاى برابر دانست، هر جند ماهيت اجر ايسى ايسن دو روش كـاملاً

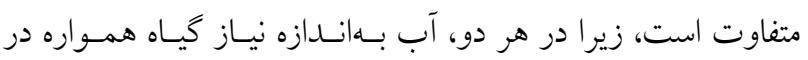

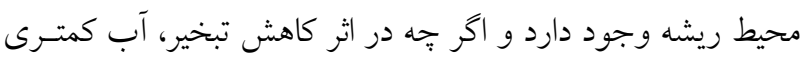

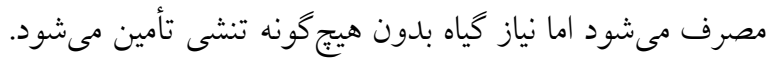

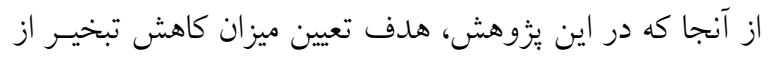

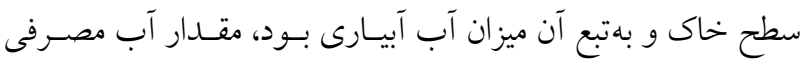

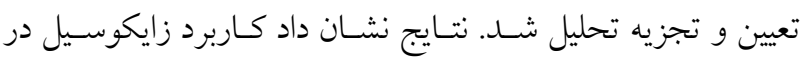

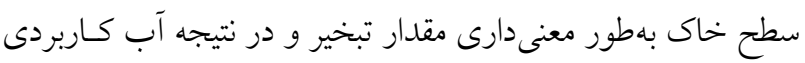

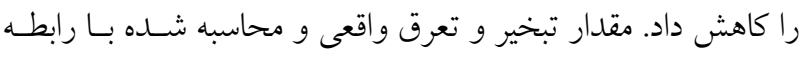

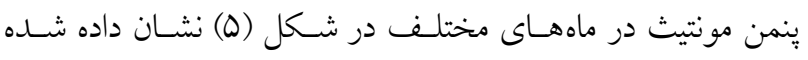

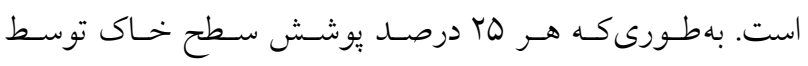

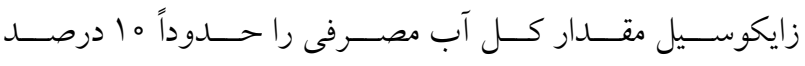

و در صورت نياز مقايسه ميانخينهاى هر صـفت بـين تيمارهـاى

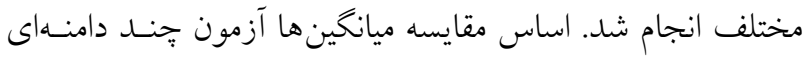
دانكن درنظر گرفته شد و نتايج در نرمافزار Excel ارائه شد.

\section{نتايج و بحث}

نتايج تجزيه واريانس نشان داد وزن تـر بوتـه، وزن خشـك بوتـه و وزن خشك ريشه در بين تيمارها در سطح بنج درصــ بـا يكـديخر

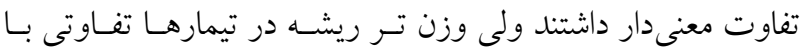
يكديخر نداشتند (جدول r). همانطور كه در شـكل (او r) نشـان داده شده است، تيمار شـاهد كمتـرين وزن تــــــــه را داشـت، در حالى كه ساير تيمارها بهطور معنى دارى وزن تر بوته در آنها بيشـتر

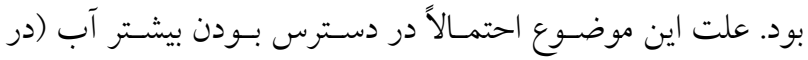

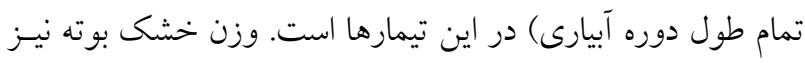

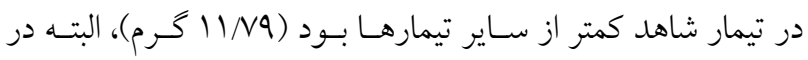

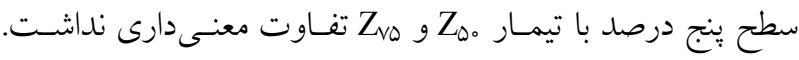
وزن خشك ريشه نيز در تيمار شاهد و_ا Z ، كمتر از سـاير تيمارهـا

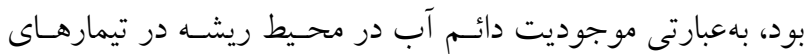

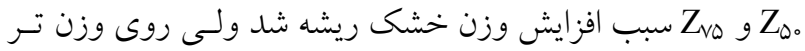

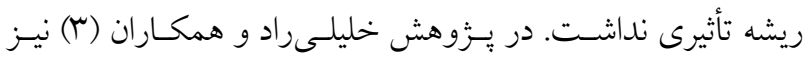

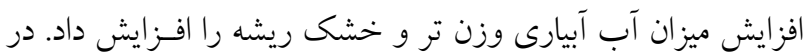
هر قسمت از خاك كه آب وجود داثته باشد، ريشه در همان نقطـه.

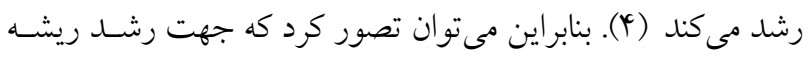

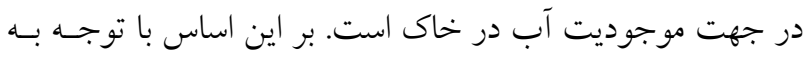

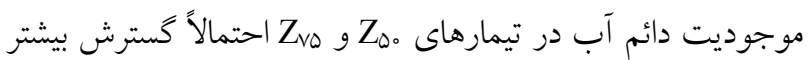
ريشه سبب افزايش وزن خشك آن شده است، همجنين طبق نظـر يير نجم الدين و همكاران (T) وجود رطوبت كافى و مناسب، رشـــ

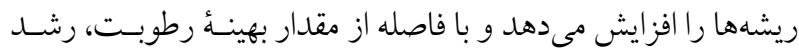

$$
\text { ريشه كاهش مى ريابد. }
$$

نتايج تجزيه واريانس تعداد فلفل ها، وزن تر آنها و عملكـرد تـر

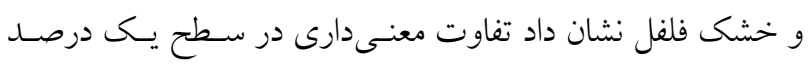

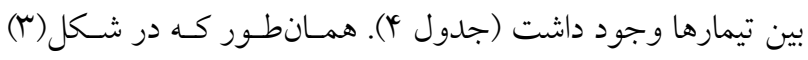

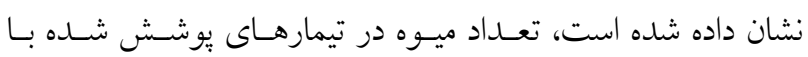


نشريه علوم آب و خاك (علوم و فنون كشاورزى و منابع طبيعى) / سال بيست و دو / شماره دو / تابستان IrqV

جدول r. نتايج تجزيه واريانس خصوصيات گياه فلفل

\begin{tabular}{|c|c|c|c|c|c|}
\hline وزن خشك ريشه & وزن تر ريشه & وزن خشك بوته & وزن تر بوته & درجه آزادى & منابع تغييرات \\
\hline $1 / \circ 0^{*}$ & $19 / 10^{\mathrm{ns}}$ & $10 / 40^{*}$ & 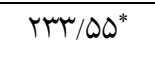 & $r$ & تيمار \\
\hline$\circ / 0 \varphi^{n s}$ & $\Delta r / q)^{n s}$ & $\circ / 9 \Lambda^{\mathrm{ns}}$ & $r \mu / Y \circ n s$ & r & بلوى بل \\
\hline$\circ / Y I V$ & $r q / 4 q$ & $1 / 91$ & $\xi \circ / \Lambda \varphi$ & 9 & خطا \\
\hline $1 / / 01$ & $4 y / 10$ & $9 / 10$ & $\mid r / 91$ & & ضريب تغييرات \\
\hline
\end{tabular}

جدول f. أنتايج تجزيه واريانس صفات اندازهيرى شده

\begin{tabular}{|c|c|c|c|c|c|}
\hline عملكرد خشك & عملكرد تر & ميانگين وزن تر ميوه & تعداد ميوه & درجه آزادى & منابع تغييرات \\
\hline 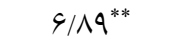 & rGY/4 $\Lambda^{* *}$ & $Y / \circ Y^{* *}$ & YI/M** & $r$ & تيمار \\
\hline $1 / \backslash \wedge^{\mathrm{ns}}$ & $10 / 4 \&$ ns & $I / \Gamma V^{*}$ & ( & r & بلوك \\
\hline $1 / 09$ & $T 1 / D 1$ & $0 /|M|$ & $1 / r T$ & 9 & خطا \\
\hline $1 N / \circ Y^{r}$ & $9 / 90$ & $\Lambda / \uparrow \Lambda$ & $10 / Y_{0}$ & & ضريب تغييرات \\
\hline
\end{tabular}

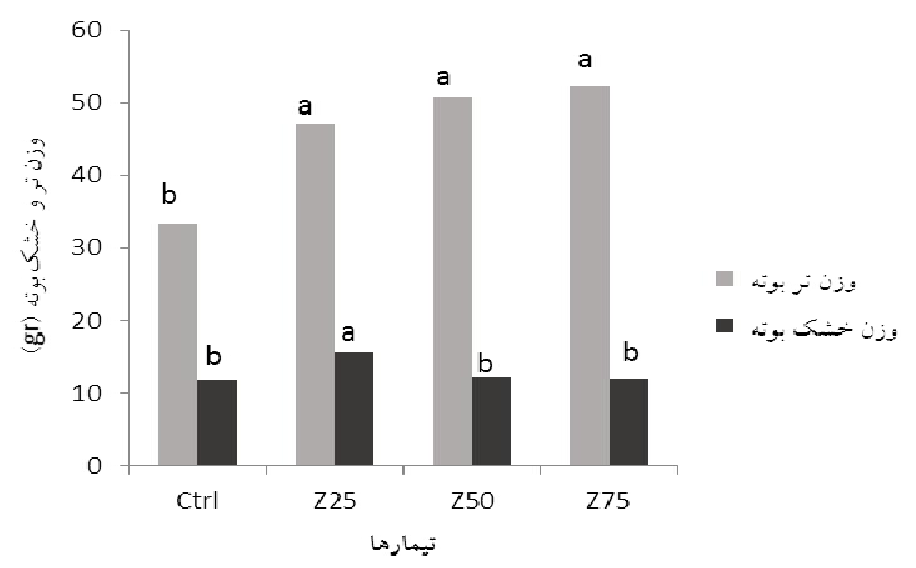

شكل ا. وزن تر و وزن خشك بوته فلفل. حروف مشتر بيانكر عدم معنىدارى در سطح احتمال بنج درصد است

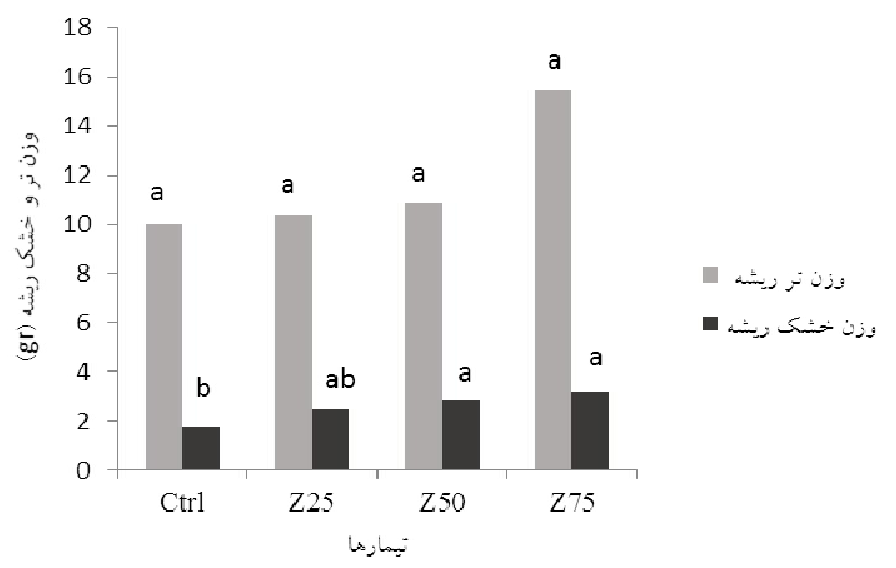

شكل r. وزن تر و وزن خشك ريشه گياه فلفل. حروف مشترى بيانكر عدم معنىدارى در سطح احتمال بنج درصد است 


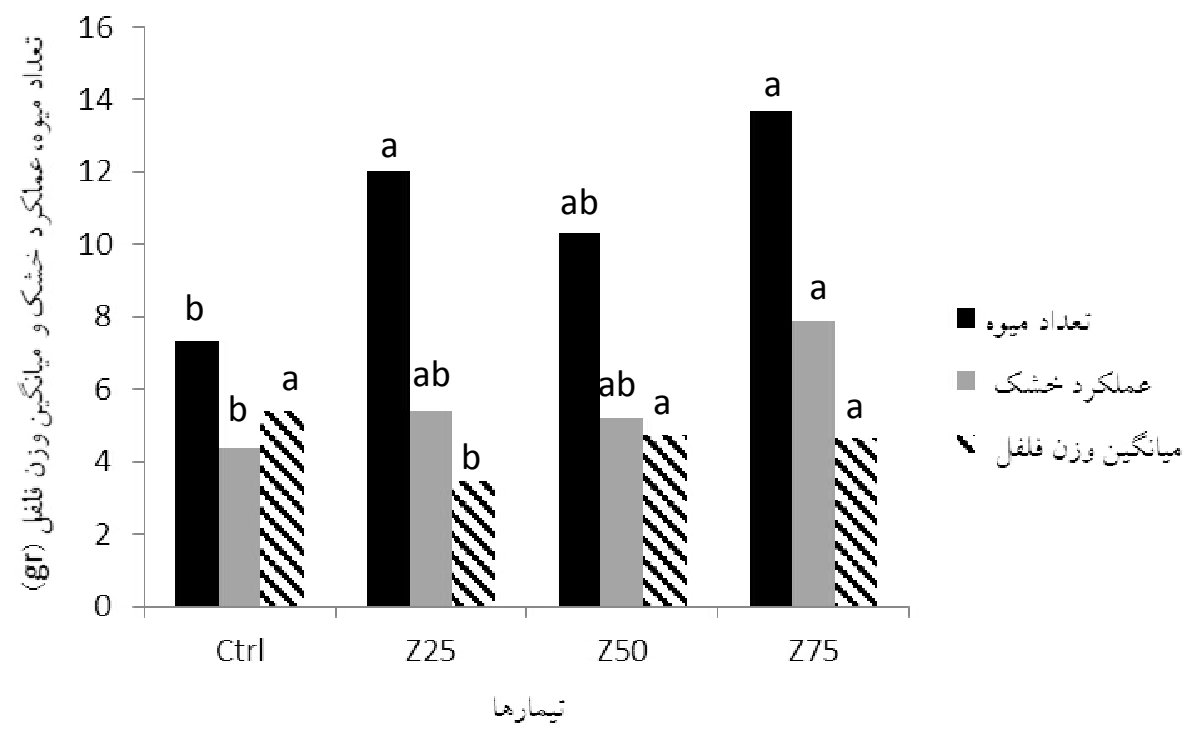

شكل r. مقايسه ميانگين تعداد ميوه، عملكرد خشك ميوه و ميانگين وزن تازه فلفل. حروف مشتر بيانكر عدم معنى دارى در سطح احتمال ينج درصد است

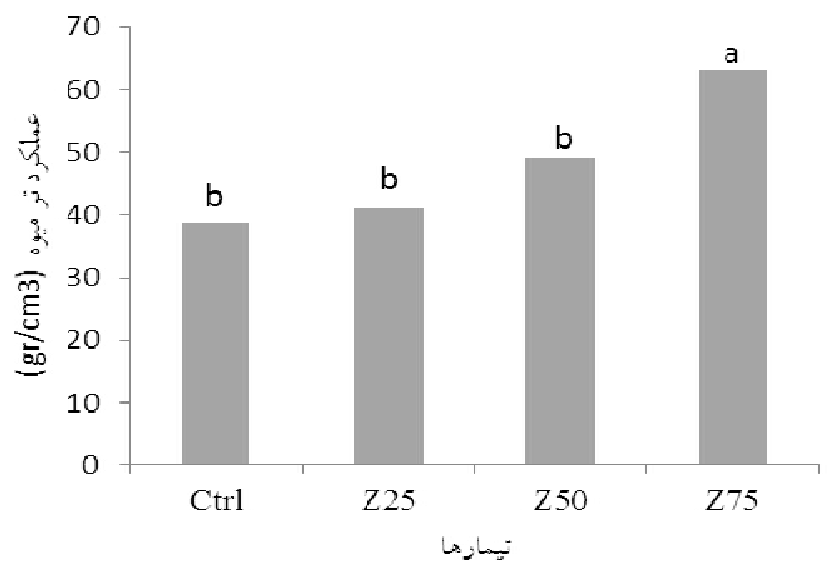

شكل f. مقايسه ميانخين عملكرد تر ميوه. حروف مشترك بيانگر عدم معنىدارى در سطح احتمال پينج درصد است

مصرفى در تيمارها در ابتداى دوره كه هوا خنكتــر و تبخيـر از

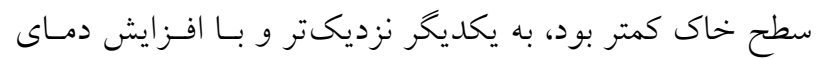

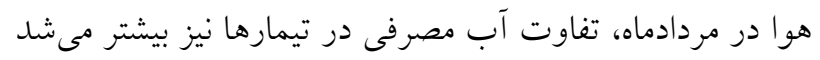

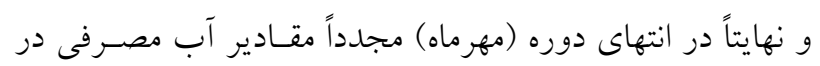

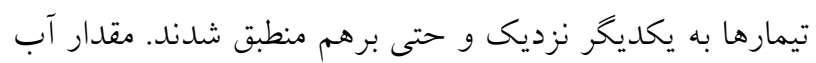

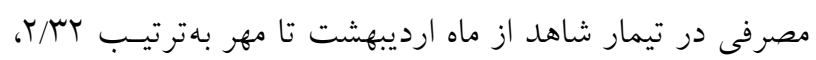

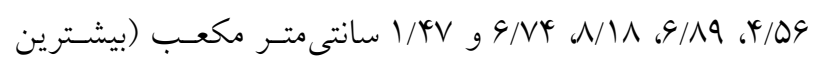
مقادير در بين تيمارها) و در تيمار Z

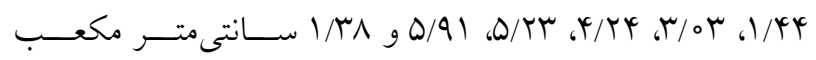

كاهش داد. بهاين ترتيـب بـالاترين ميـزان آب در تيمـار شـاهد

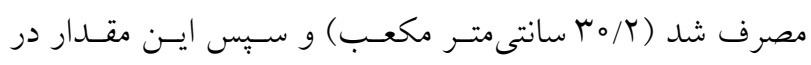
تيمار

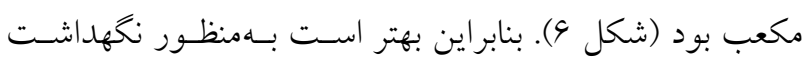

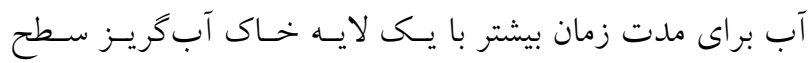

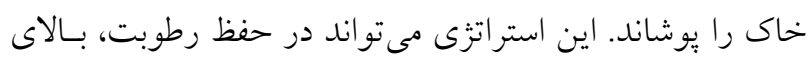

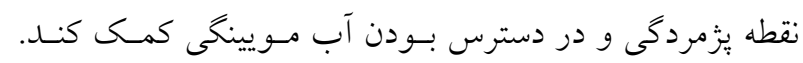

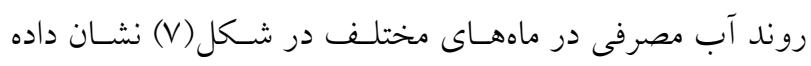

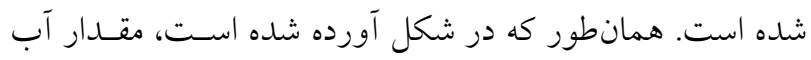




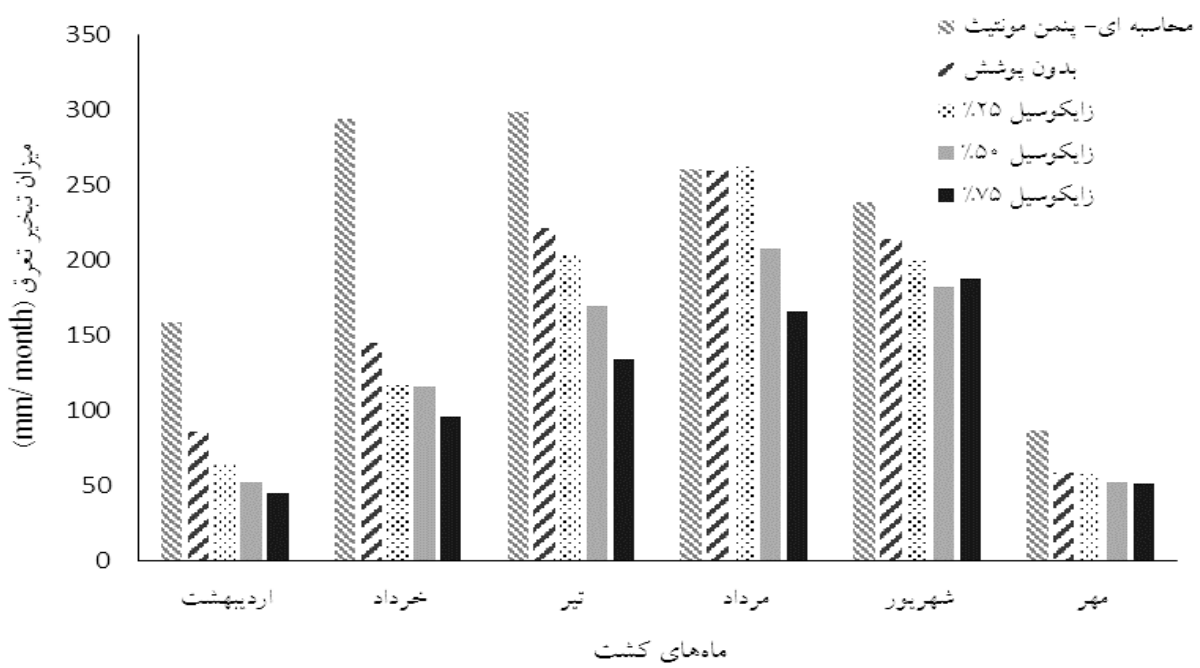

شكل ه. ميزان تبخير و تعرق محاسبهاى و تبخير تعرق واقعى در تيمارهاى مختلف

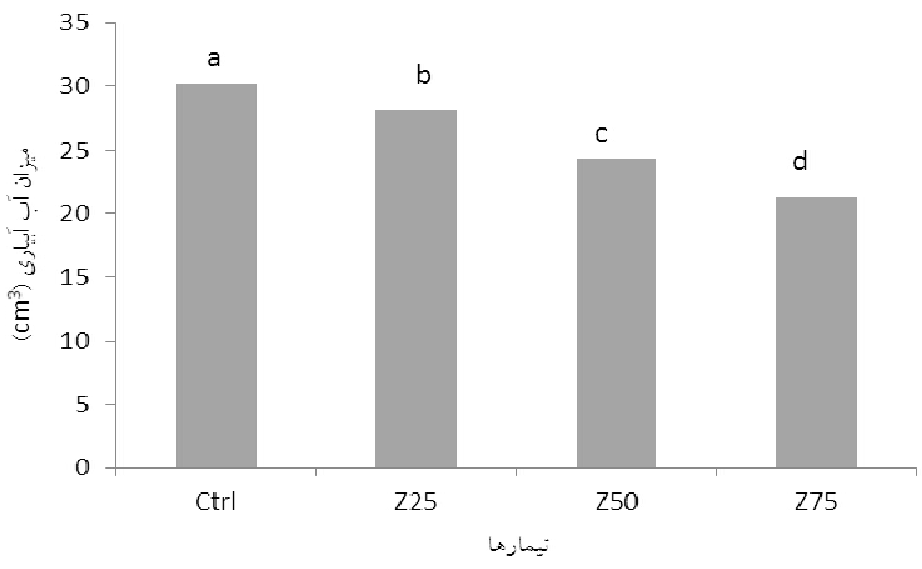

شكل 9. ميزان آب آبيارى در تيمارهاى مختلف. حروف مشترى بيانكر عدم معنىدارى در سطح احتمال ينج درصد است

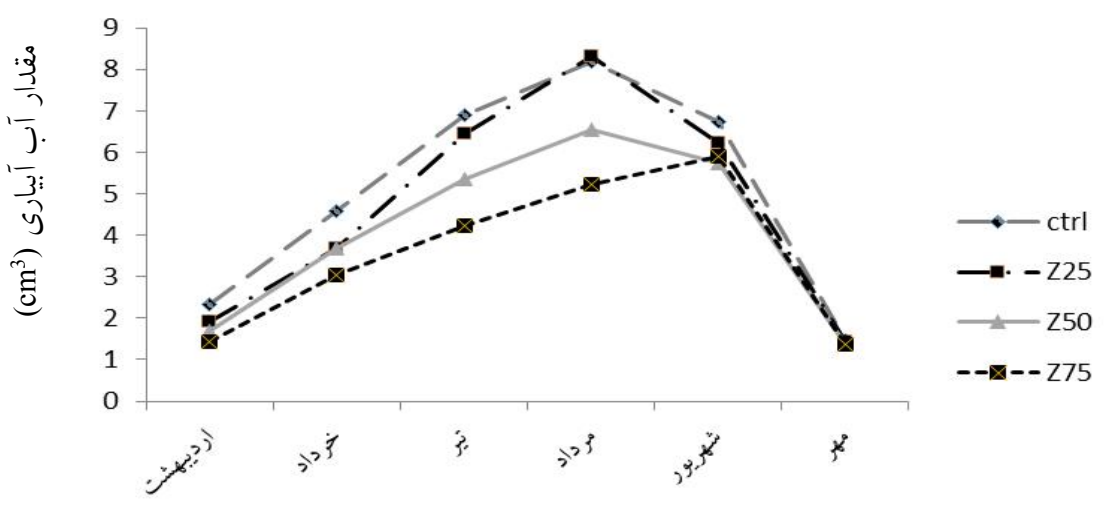

ماoهاى كشت

شكل V. مقدار آب آبيارى در ماههاى مختلف (اواسط ارديبهشت تا اواسط مهرماه) 


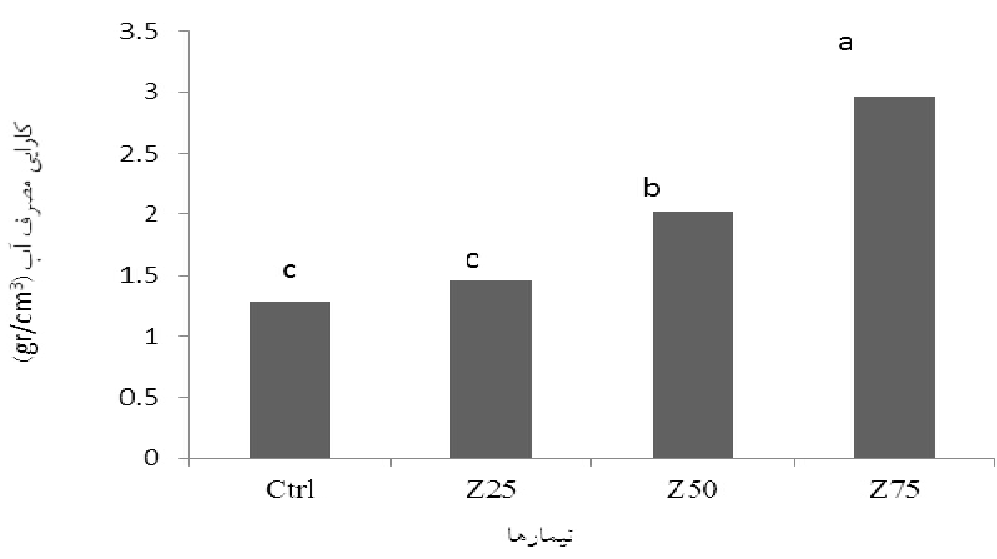

شكل ^. كارايى مصرف آب در تيمارها. حروف مشترك بيانگر عدم معنىدارى در سطح احتمال بنج درصد است

\section{نتيجه گيرى}

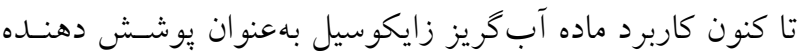
سطح خاك و تأثير آن بر كياه مورد بررسى قـرار نخرفتـه اسـت.

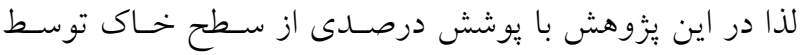

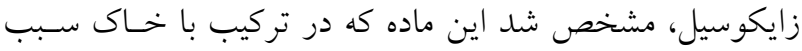

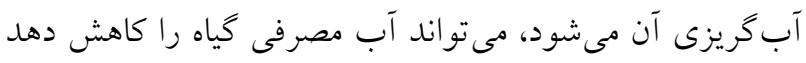
بهطورى كه هر rD درصد يوشش سطح خاك توسط زايكوسـيل

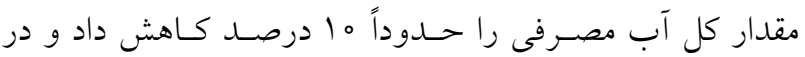

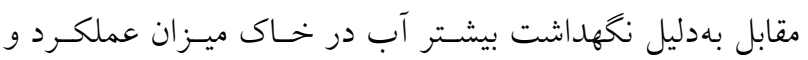
كارايى مصرف آب را افزايش داد. به اين ترتيب بالاترين ميـزان آب در تيمار شاهد مصرف شد و سيس اين مقدار در تيمارهاى

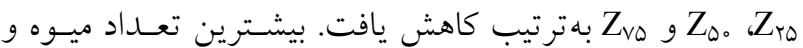
بالاترين عملكرد خشك نيز در تيمـار بـا بوشـش VQ درصــى سطح خاك توسط زايكوسيل بهدست آمد.

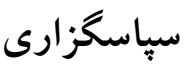

از رياست و معاونت علمى و يزوهشى دانشخاه بيام نور بهدليـل حمايت مالى از اين بزّوهش، قدردانى مىشود.
(كمترين مقادير در بين تيمارها) بود. در بررسى رى و اسـمتم

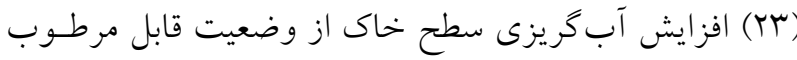
شدن به سمت آب گريزى اندك و متوسط باعـث شـد، تبخيـر

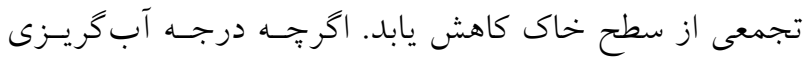
بالا تفاوتى با درجه آبكريزى متوسـط از نظـر ميـزان تبخيـر نداشت.

$$
\text { كارايى مصرف آب }
$$

كارايى مصرف آب در تيمارهاى مختلف تفـاوت معنسىدارى

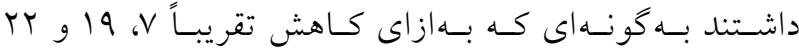
درصدى آب بهاهترتيب در تيمارهـاى

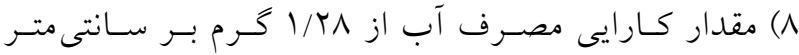

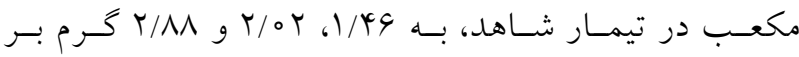
سانتى متر مكعب بهت تيب در تيمارهاى Z بنابر اين كـاهش مصـرف آب نــه تنهـا باعـث كـاهش توليــ محصول نشد، بلكه بهدليل كاهش تبخير و افزايش نخهماشت آب در محيط ريشه در طول دوره رشـد، سـبب افـزايش آن

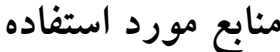
ا. بابازاده، ح.، ع. عبدزادكوهرى و آ. خنك. \& qجا. اثر مديريت آبيارى و سطوح مختلف مالج كاه بر عملكرد و اجزاى عملكرد گياه لوبيا. مجله يثزوهش آب در كشاورزى 


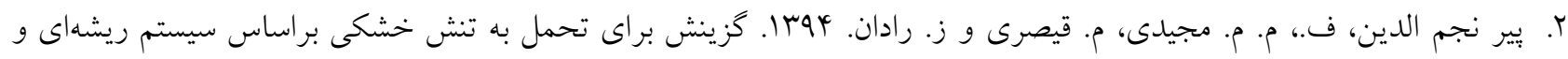

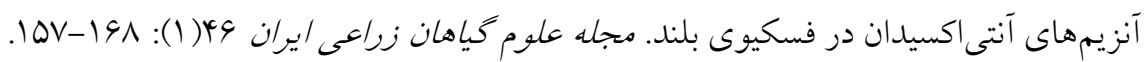

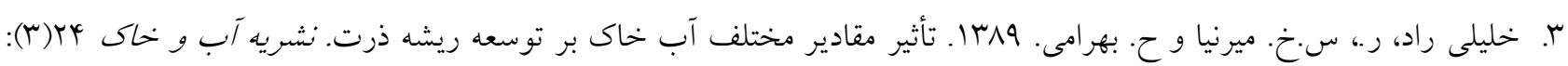

$$
\begin{aligned}
& . \Delta Q V-Q Y Y
\end{aligned}
$$

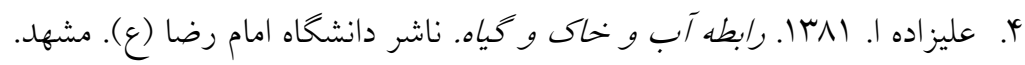

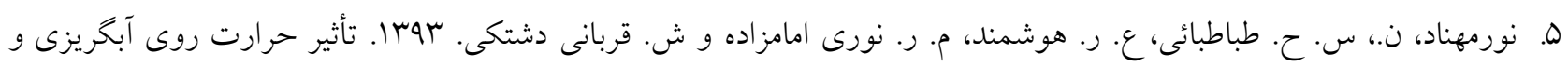

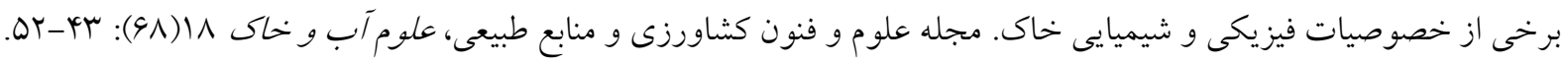

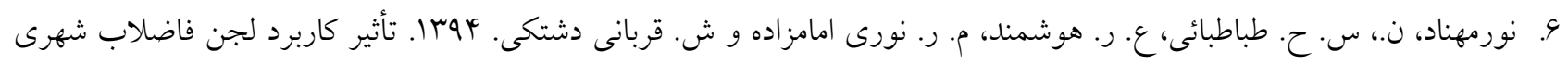

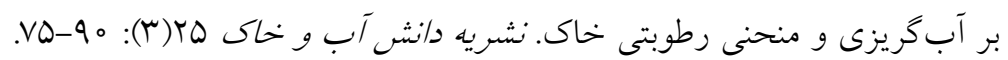

7. Allen, R. G., L. S. Pereira, D. Raes and M. Smith. 1998. Crop Evapotranspiration Guidelines for Computing Crop Water Requirements. FAO Irrigation and Drainage Paper No. 56, FAO, Rome, Italy.

8. Fernandez, M. D., S. GallardoM, S. Bonachwla, F. Orgaz, R. B. Thompson and F. Fereres. 2005. Water use and production of a greenhouse pepper crop under optimum and limited water supply. Horticultural Science Journal 104: 220-247.

9. Dekker, L. W. and P. D. Jungerius. 1990. Water repellency in the dunes with special reference to The Netherlands. Catena 18: 173-183

10. FAO. 2007. Production Year Book. Food and Agriculture Organization of United Nations, Rome, Italy.

11. Feng, L. S., Z. X. Sun, C. R. Yan, M. Z. Zheng, J. M. Zheng, N. Yang, L. W. Bai and C. Feng. 2015. Effect of farmland surface covered porous mulch materials on soil water, heat and water use efficiency of maize. Journal of Animal and Plant Science 25: 22-27.

12. Fink, D. H., K. R. Cooley and G. W. Frasier. 1973. Wax-treated soils for harvesting water. Journal Range Management 26: 396-398.

13. Garcia-Corona, R., E. Benito, E. De Blas and M. E. Varela. 2004. Effects of heating on some soil physical properties related to its hydrological behavior in two northwestern Spanish soils. International Journal of Wildland Fire 13: 195-199.

14. Goebel, M. O., S. K. Woche, J. Bachmann, A. Lamparter and W. R. Fisher. 2007. Significance of wettabilityinduced changes in microscopic water distribution for soil organic matter decomposition. Soil Science Society of America Journal 71: 1593-1599.

15. Gupta, B., D. O. Shah, B. Mishra, P. A. Joshi, G. G. Vimal and R. S. Fougat. 2015. Effect of top soil wettability on water evaporation and plant growth. Journal of Colloid and Interface Science 449: 506-513.

16. Hunter, A. 2011. Investigation of water repellency and critical water content in undisturbed and reclaimed soils from the Athabasca oil sands region of Alberta, Canada. MSc. Thesis, University of Saskatchewan.

17. Khan, M. A. I., A. M. Farooque, M. A. Haque, M. A. Rahim and M. A. Hoque. 2008. Eeffects of water stress at various growth stages on the Physio-morphological characters and yield in chilli. Bangladesh Journal of Agriculture Research 33(3): 353-362.

18. Letey, J., M. L. K. Carrillo and X. P. Pang. 2000. Approaches to characterize the degree of water repellency. Journal of Hydrology 231-232: 61-65.

19. Owusu S. J. D., P. Asante and P. Osei-Bonsu. 2010. Water requirement, deficit irrigation and crop coefficient of hot pepper (Capsicum frutescens) using irrigation interval of four (4) days. Journal of Agricultural and Biological Science 5: 72-78.

20. Peng, Z., W. Ting, W. Haixia, W. Min, M. Xiangping, M. Siwei, Zh. Rui, J. Zhikuan and H. Qingfang. 2015. Effects of straw mulch on soil water and winter wheat production in dryland farming. Scientific Reports 5: 10725.

21. Pervaiz, M. A., M. Iqbal, K. Shahzad and A. U. Hassan. 2009. Effect of mulch on soil physical properties and N, P, $\mathrm{K}$ concentration in maize (Zea mays L.) shoots under two tillage systems. International Journal of Agriculture and Biology 11: 119-124.

22. Quyum, A. 2000. Water migration hydrophobic through soils. MSc. Thesis, Department of Civil Engineering. Calgary, Alberta.

23. Rye, C. F. and K. R. J. Smettem. 2017. The effect of water repellent soil surface layers on preferential flow and bare soil evaporation. Geoderma 289: 142-149.

24. William, J. 1993. Plastic Mulches for the Production of Vegetable Crops. Hort Technology 1: 35-39.

25. www.Zycosil.ir 


\title{
The Effect of Zycosil on Water Consumption and Yield of Pepper (Capsicum annuum L.)
}

\author{
N. Nourmahnad ${ }^{1 *}$ \\ (Received: January 20-2017; Accepted: August 14-2017)
}

\begin{abstract}
Due to the water scarcity in Iran, it is important to provide strategies to reduce water consumption in the agriculture sector. Zycosil is a nanotechnology material that makes a great hydrophobe in the soil. This study was conducted based on completely randomized block design within microlysimeter with the height of $15 \mathrm{~cm}$ and the diameter of $8 \mathrm{~cm}$ to investigate the hydrophobic effect on the amount of consumed water in pepper. Sweet pepper seedlings were planted in them; then the treatments were applied. The Z25, Z50 and Z75 treatments consisted of covering 25,50 and $75 \%$ of the soil surface by Zycosil; these were compared with the control (Ctrl- no Zycosil application) in three replications. The results showed that Z75 treatment reduced $27 \%$ water consumption and increased the fresh yield by approximately 62 $\%$. The increased yield of Z25 and Z50 was 5 and $26 \%$, respectively. Dry pepper yield was increased in Z25, Z50 and Z75 treatments by 22,19 and $80 \%$, respectively, as compared to Ctrl treatment. The amount of water consumed was decreased by $10 \%$ per $25 \%$ coverage level. The least amount of water use efficiency was observed in the control treatment $(1.28 \mathrm{gr} / \mathrm{cm} 3)$. The Z75 had the highest water use efficiency $(2.96 \mathrm{gr} / \mathrm{cm} 3)$. Hence, the application of hydrophobic material such as Zycosil in the soil surface reduced water evaporation and increased water retention. This increased the yield and water use efficiency.
\end{abstract}

Keywords: Hydrophobic, Water use efficiency, Zycosil, Yield, Pepper

1. Department of Agriculture, Payame Noor Univesity, Iran.

*: Corresponding Author, Email: Negar_Nourmahnad@yahoo.com 